\section{METHODOLOGY TO PROMOTE INTERAGENCY WORK BETWEEN COMMUNITARIAN ORGANISATION AND GOVERNMIENT. EXPERIENCE FROM CALI, COLOMBIA}

doi:10.1136/injuryprev-2012-040580a.27

K Galvis*, A Osorio, L Nieto Gil, I Gutiérrez María.

Background During a pilot intervention in Cali, Colombia was designed a methodology to promote collaborative work at the communitarian level, at the governmental level and between them. First of all, there was a process to identify priority issues, zones in the community, and age groups. Those were identified by three communitarian groups and a group of governmental representatives.

Aims/Objectives/Purpose To promote collaborative work at communitarian and governmental level to reduce injury prevention. To create a new scenario to approach communitarian initiatives and governmental interventions focus on same issues, zones and populations groups. Methods There was designed a workshop methodology to meet the groups that are developing programmes in the same zone, issues and age groups. They were divided in four round tables with one moderator. Each representative from the government and the community was invited to present their work on injury and violence prevention finding common experiences that are going on in same issues, zones, and ages groups. Those which are suitable to work in a collaborative way sign a partnership agreement.

Results/Outcome There was a great participation from all levels, 40 agreements were signed and more collaborative work was reach after this experience. The methodology will be reply in more communitarian groups this year

Significance/Contribution to the Field This experience can be reply in others countries to promote multi-sectorial approaches for injury and violence prevention. Strengthening common experiences in the same field it is a crucial factor to make more effective injury preventions programmes. 